recognised. The objective is to look at the causes of injury mortality among Pakistani women.

Methods DHS in Pakistan was conducted from September 2006 till February 2007. The survey adopted a two-stage, stratified, random sample design. It included 95000 households out of which a total of 1125 female deaths (12-49 years) were identified since January 2003. Verbal Autopsy questionnaires were successfully completed for 1062 females. All of the causes of death were coded according to the International Classification of Diseases, 10th version (ICD-10). Result There were 66 (6\%) deaths reported in PDHS 2006-2007 due to injuries. Of the 65 females, 47 had died due to RTIs, 9 due to burns/corrosions and 9 due to violence. These injuries were more common in younger women than older women affecting women between 12 and 35 years old (75\%). Injury mortality was found to be almost twice as common in rural women compared to urban women ( $65 \%$ vs $35 \%$ ) especially in case of RTI ( $68 \%$ in rural vs $32 \%$ in urban). Women with burns and violence were mostly home bound (burns $=100 \%$ and violence $=89 \%$ ) while nearly $38 \%$ of women died due to RTI were working. Most women with injuries were married (61\%) and majority of their husbands had attended school as well (RTI $=56.7 \%$, burns $=80 \%$ and violence $=66.7 \%$ ).

Conclusion Injuries are common cause of deaths in younger Pakistani women.

\section{P2-521 ASSESSMENT OF AVAILABLE INFRASTRUCTURE FOR MAINTENANCE OF HYGIENE IN POULTRY BUTCHERS SHOPS FOR HEALTHY MEAT PRODUCTION IN BIHAR, INDIA}

doi:10.1136/jech.2011.142976m.48

R Kumar.* IDSP, Pauri, Uttarakhand, India

Introduction Infrastructure of a butcher shop is important in maintaining meat hygiene and preventing the meat as vehicle for zoonotic and infectious diseases. The objective of the study was to assess the infrastructure available to poultry butchers for maintenance of meat hygiene.

Methods Two poultry meat shops were randomly selected from each of the 57 wards of Patna city. Their infrastructural details were obtained by observing the shop and activities involved for one hour by principal investigator.

Results Among total 113 shops studied (One is missing), 35 (31\%) shops were in open space. 106 (93.8\%) shops were located in market areas. Only 30 (26.5\%) shops have availability of adequate quantity of potable water supply. Only one shop have hot water supply. 9 (8\%) facilities have disinfectant and $20(17.7 \%)$ of them have soaps in the shop at the time of study. $71(68 \%)$ of shops have adequate light supply and detergent been presented in their shops. Only 61 (54\%) and $26(23 \%)$ of butchers have given opinion to be cleanliness of setting and equipments for hygienic meat production respectively.

Conclusion Infrastructure available for poultry butchering was very much inadequate in most of the shops. There is imminent need of provision of strict regulation for maintaining good infrastructure and education to butchers about hygienic meat production to protect all meat borne diseases and associated occupational hazards.

\section{P2-522 SOIL TRANSMITTED HELMINTH INFECTIONS IN PRESCHOOL AND SCHOOL AGED CHILDREN IN EKITI AND ILE-IFE, SOUTHWEST NIGERIA}

doi:10.1136/jech.2011.142976m.49

O Sowemimo,* S Asaolu. Department of Zoology, Obafemi Awolowo University, lle-Ife, Nigeria

Introduction Soil transmitted helminths are among the neglected tropical diseases prevalent in developing countries, and children are the most vulnerable. The objective of the cross-sectional study was to determine the prevalence and intensity of soil-transmitted helminths (STHs) in preschool and school aged children in Ile-Ife and Ekiti.

Methods Faecal samples (511) were collected between May and July 2010 and processed using modified Kato - katz technique.

Results The overall prevalence of STH infection was $29.2 \%$. Ascaris lumbricoides (28.4\%) was the most prevalent, and were observed; 136 (26.6\%) either alone or together with Trichuris trichiura and/or hookworm infections. Prevalences of A lumbricoides ranged from $6.7 \%$ to $47.5 \%$, T trichiura from 1.3 to $4.9 \%$ and hookworms from 0.5 to $4.9 \%$ in the four schools. The prevalences of A lumbricoides, T trichiura and hookworms were 28.4, 3.1 and $1.8 \%$ respectively. Intensity determined by egg count per gram of faeces (epg) \pm SEM were $939.84 \pm 122.62$ for A lumbricoides, $0.03 \pm 0.01$ for $T$ trichiura and $0.02 \pm 0.01$ for hookworm. There was no significant difference between sex and prevalence of $A$ lumbricoides. The prevalence of A lumbricoides rose from $8.1 \%$ in children aged $2-3$ years and reached the peak $(75.0 \%)$ in children 12 years and above.

Conclusion The findings from this study showed that STH infections are endemic in the schools investigated and urgent interventions involving both preschool and school children such as deworming and health education are recommended.

\section{P2-523 RESIDENTIAL SEGREGATION AND MENTAL HEALTH IN A POST CONFLICT SOCIETY}

doi:10.1136/jech.2011.142976m.50

${ }^{1}$ A Maguire, ${ }^{*} \mathrm{D}$ French, ${ }^{1} \mathrm{D}$ O'Reilly. ${ }^{1}$ Centre for Public Health, Department of Epidemiology Queen's University, Belfast, UK; ${ }^{2}$ Queen's University Management School, Belfast, UK

Introduction Research shows conflict and racial/ethnic segregation leads to poor health. Northern Irelands emerging from over 30 years of civil disturbance but remains a society markedly segregated along religious lines with $>70 \%$ population living in areas comprising $>70 \%$ one religion. This study aims to determine if segregation is an independent predictor of psychological morbidity.

Methods A geographical information system was used to produce a dissimilarity index for the 890 super-output areas (SOA) in Northern Ireland (average pop. 1900), modelling residential segregation by measuring dissimilarity within a SOA compared to its surrounding SOAs. Population was divided into equally proportioned segregation deciles. Psychological morbidity was assessed using uptake of antidepressant and anxiolytic medication data from a population-wide electronic prescribing system over 14 months (2009/10). Multiple logistic regression of $\sim 1.2$ million non-institutionalised patients aged 18-74 was executed, with adjustment for demographic factors, residential social fragmentation, deprivation, and multi-level modelling to adjust for variations in prescribing at general practice level.

Results Almost 20\% patients were prescribed antidepressant and/or anxiolytic medication. Likelihood of antidepressant and anxiolytic use was higher in segregated than non-segregated areas $(\mathrm{OR}=1.45$ 95\% CI 1.35 to 1.56 and OR=1.49 95\% CI 1.32 to 1.68 respectively) after adjusting for age and gender. Further adjustment for fragmentation and income deprivation eliminated the relationship $(\mathrm{OR}=1.0295 \%$ CI 0.96 to 1.08 and $\mathrm{OR}=1.0095 \%$ CI 0.90 to 1.10 respectively).

Conclusion Segregation is related to poor mental health but only because the people living in the more segregated areas are economically disadvantaged. Further analysis is being undertaken to determine if this holds true for other measures of residential polarisation. 